\section{FEATURE}

\section{Joanna Woods}

\section{Office for National Statistics}

\section{SUMMARY}

Standard errors are used to calculate the difference between the estimate and its true population growth rate. They are one way of measuring the quality of a price index. This article looks at the standard errors for the output producer price index (PPI), the monthly index measuring growth in UK factory gate prices. It provides an update of the estimates of the standard errors for month-on-month and 12-month growth rates of the gross sector output PPI. The article presents the main findings from the analysis, along with an explanation of other aspects of the quality of price indices.

\title{
Measuring the quality of the producer price index - an update
}

his article provides an update to the previously published article

'Measuring the quality of the producer price index', Morris and Green (2007), using growth rates from July 2006 to June 2007. The output producer price index (PPI), produced by the Office for National Statistics (ONS), is a monthly index that measures the growth in UK factory gate prices. The overall standard error for the month-on-month growth rate of the gross sector output (GSO) PPI (including duty) was 0.2 percentage points. The standard error for the 12-month growth rate was 0.6 percentage points.

\section{Ensuring the quality of a price index}

Price indices are exposed to several sources of potential error. As sample surveys, price indices are vulnerable to both sampling error and non-sampling error. In addition, they are further exposed to a range of price index-specific biases.

Non-sampling error may be encountered through a variety of sources. For example:

- the observation of any data, including prices, is subject to measurement error and response error

- the list of businesses which form the sample frame may be incomplete or out-of-date

- the failure of some respondents to participate in the survey exposes the resulting statistics to non-response bias
ONS employs sound principles in the design of surveys to mitigate against these sorts of biases. Questionnaire design principles help reduce measurement error. The construction of the sample frame is based on the Products of the European Community (PRODCOM) survey, which itself adopts the Inter-Departmental Business Register, ensuring that the sample is drawn from the most complete and contemporary data set available in the UK.

Price indices such as the PPI that are constructed using a 'fixed basket approach' are further subject to specific types of bias. These include:

- substitution bias, that potentially arises because producers change the types of goods they produce

- new item bias, that potentially arises because of the introduction of revolutionary goods into the market place (historic examples include video recorders and microwave ovens)

- quality change bias, that potentially arises because of changes to the product or changes to the production function

As with other sources of non-sampling error, it is not generally possible to measure directly the impact of these types of biases. Instead, ONS takes steps to mitigate these biases: the sample of businesses from which the fixed basket is constructed is updated annually to reflect findings from the latest PRODCOM enquiry - PRODCOM literally serves as the first phase of sampling, so 
that the types of product included in the basket better reflect recent activity. This process helps mitigate the various types of substitution bias. Quality change bias is mitigated through detection of specification changes, which then allow quality adjustment where appropriate. In the special case of computers, hedonic price indexes, which are used to value changes in quality of high-technology goods, are constructed to allow for the rapid quality changes observable in this sector.

Beyond the types of non-sampling error, and those errors specific to price

\section{Table 1}

\section{Month-on-month growth rates and standard errors: by division}

\begin{tabular}{|c|c|c|c|}
\hline $\begin{array}{l}\text { Two digit } \\
\text { (division) }\end{array}$ & $\begin{array}{r}\text { Month } \\
\text { growth, } \\
\text { (pe }\end{array}$ & $\begin{array}{l}\text { nonth } \\
2007 \\
\text { tages) }\end{array}$ & $\begin{array}{r}\text { Standard error of the } \\
\text { month-on-month } \\
\text { growth, } \\
\text { 12-month average, } \\
\text { July } 2006 \text { to June } 2007 \\
\text { (percentage points) }\end{array}$ \\
\hline \multicolumn{4}{|l|}{ All } \\
\hline manufacturing & Gross sector output including duty & 0.4 & 0.2 \\
\hline 15 & Food products and beverages including duty & 0.3 & 0.2 \\
\hline 16 & Tobacco products including duty & 0.0 & 0.0 \\
\hline 17 & Textiles & 0.1 & 0.1 \\
\hline 18 & Wearing apparel & 0.0 & 0.1 \\
\hline 19 & Leather and leather products & 0.3 & 0.2 \\
\hline 20 & Wood and wood products & 1.0 & 0.4 \\
\hline 21 & Pulp paper and paper products & 0.1 & 0.2 \\
\hline 22 & Printed matter and recorded media & -0.1 & 0.1 \\
\hline 23 & Petroleum products including duty & 1.6 & 0.9 \\
\hline 24 & Chemicals, chemical products and man-made fibres & 0.2 & 0.2 \\
\hline 25 & Rubber and plastic products & -0.1 & 0.1 \\
\hline 26 & Other non-metallic mineral products & -0.1 & 0.3 \\
\hline 27 & Base metals & -0.2 & 0.5 \\
\hline 28 & Fabricated metal products, except machinery and equipment & 0.7 & 0.2 \\
\hline 29 & Machinery and equipment not elsewhere classified & -0.1 & 0.1 \\
\hline 30 & Office machinery and computers & -0.2 & 1.2 \\
\hline 31 & Electrical machinery and apparatus not elsewhere classified & 0.3 & 0.2 \\
\hline 32 & Radio, television, and communication equipment and apparatus & -1.4 & 0.3 \\
\hline 33 & Medical precision and optical instruments, watches and clocks & -0.2 & 0.1 \\
\hline 34 & Motor vehicles, trailers and semi-trailers & -0.1 & 0.1 \\
\hline 35 & Other transport & 0.3 & 0.2 \\
\hline 36 & Furniture: other manufactured goods not elsewhere classified & 0.1 & 0.1 \\
\hline 37 & Recovered secondary raw materials & 0.8 & 3.1 \\
\hline
\end{tabular}

Figure 1

Month-on-month growth rates: by division, June 2007, with approximate 95 per cent confidence intervals, July 2006 to June $2007^{1}$

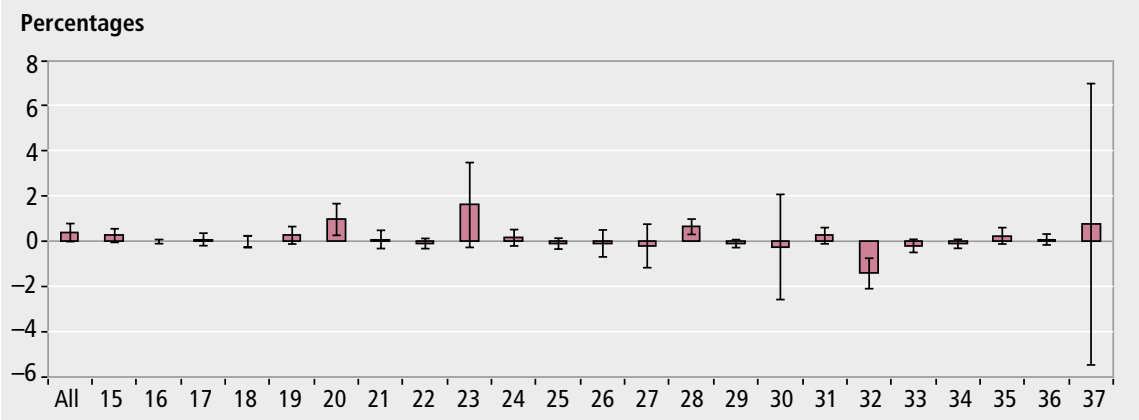

Note:

1 12-month average. that are likely to be obtained when taking a sample. The use of standard errors provides a method of assessing the precision of the estimate - the lower the standard error, the more confident one can be that the estimate of the average price growth is close to the true population value.

\section{Estimating standard errors}

The following section summarises how the standard error for the PPI is calculated. For a more complete description, see Wood et al (2008).

The PPI is based on the estimation of average price movements for a fixed and representative sample of products. A new method for estimating standard errors of growth, over any fixed time, was first published in 2007. The concept of this method was that the PPI could be expressed as a function of monthly growth rates of the price relatives. The means, variances, and covariances between these growth rates are then modelled to provide the monthly standard error. For a 12-month estimated standard error, the growth rates are based on the estimated variance-covariance matrix of the monthly growth over the 12-month period. Quality adjustment is used to produce the standard errors in this analysis and no modelling error for the actual adjustment has been explicitly allowed for.

\section{Analysis and results}

Table 1 presents the overall GSO (including duty) PPI and the divisional PPI monthon-month percentage growth rates along with their standard errors. The median divisional standard error of the month-onmonth growth was 0.2 percentage points. As was the case in June 2006, divisions $23,27,30$ and 37 had particularly large standard errors due to high variations of price movements within the component subcategories.

Figure 1 shows the month-on-month growth rates in June 2007, along with an approximate 95 per cent confidence interval of \pm 2 standard errors. The confidence intervals were calculated from the individual observations of interest at the divisional level. This illustrates that the divisions with the larger growth rates have a greater standard error, particularly divisions 23, 27, 30 and 37. Division $37 \mathrm{had}$ a very large standard error because prices for copper and aluminium behave very differently from those of steel and they are all included in the same subcategory. The confidence intervals were used to test the null hypothesis, that the growth rate was 
equal to zero, with an alternative hypothesis that the growth rate was not equal to zero. From Figure 1, it was clear that all but three divisions (20, 28 and 32) should retain the null hypothesis, that the growth rate was equal to zero, because their confidence intervals include zero. However, some caution must be applied to this statement as the confidence intervals are themselves estimates, and most of them fall very closely to zero. On the other hand, divisions 30 and 37 have much wider intervals and the data show no strong evidence to suggest a nonzero growth rate.
Table 2 shows the overall GSO (including duty) PPI and the divisional PPI 12-month percentage growth rates along with their standard errors. The median divisional standard error of the 12-month growth rate was 0.6 percentage points. The GSO growth rate was four times higher than its standard error, indicating that there was some real distinguishable movement over the year. Divisions 23, 27, 30 and 37 have particularly large standard errors; division 32 was also quite high.

Figure 2 shows the 12-month growth rate in June 2007, along with an approximate 95

\section{Table 2}

\section{2-month growth rates and standard errors: by division}

\begin{tabular}{|c|c|c|c|}
\hline $\begin{array}{l}\text { Two digit } \\
\text { (division) }\end{array}$ & $\begin{array}{r}\text { Twelve-mon } \\
\text { (pe }\end{array}$ & $\begin{array}{r}\text { inth growth, } \\
\text { June } 2007 \\
\text { ercentages) }\end{array}$ & $\begin{array}{r}\text { Standard error of the } \\
\text { twelve-month growth, } \\
\text { 12-month average, } \\
\text { July } 2006 \text { to June } 2007 \\
\text { (percentage points) }\end{array}$ \\
\hline \multicolumn{4}{|l|}{ All } \\
\hline manufacturing & Gross sector output including duty & 2.4 & 0.6 \\
\hline 15 & Food products and beverages including duty & 3.7 & 0.5 \\
\hline 16 & Tobacco products including duty & 4.2 & 0.6 \\
\hline 17 & Textiles & 1.8 & 0.5 \\
\hline 18 & Wearing apparel & 0.3 & 0.7 \\
\hline 19 & Leather and leather products & 0.9 & 1.0 \\
\hline 20 & Wood and wood products & 10.2 & 1.0 \\
\hline 21 & Pulp paper and paper products & 3.9 & 0.6 \\
\hline 22 & Printed matter and recorded media & 1.4 & 0.4 \\
\hline 23 & Petroleum products including duty & -0.3 & 4.1 \\
\hline 24 & Chemicals, chemical products and man-made fibres & 1.6 & 0.6 \\
\hline 25 & Rubber and plastic products & 1.0 & 0.5 \\
\hline 26 & Other non-metallic mineral products & 4.5 & 0.9 \\
\hline 27 & Base metals & 9.6 & 1.9 \\
\hline 28 & Fabricated metal products, except machinery and equipment & 4.6 & 0.5 \\
\hline 29 & Machinery and equipment not elsewhere classified & 2.8 & 0.4 \\
\hline 30 & Office machinery and computers & -5.0 & 4.7 \\
\hline 31 & Electrical machinery and apparatus not elsewhere classified & 1.8 & 0.7 \\
\hline 32 & Radio, television, and communication equipment and apparatus & -3.2 & 1.2 \\
\hline 33 & Medical precision and optical instruments, watches and clocks & 0.4 & 0.6 \\
\hline 34 & Motor vehicles, trailers and semi-trailers & -0.7 & 0.4 \\
\hline 35 & Other transport & 4.7 & 0.8 \\
\hline 36 & Furniture: other manufactured goods not elsewhere classified & 2.6 & 0.5 \\
\hline 37 & Recovered secondary raw materials & 16.3 & 14.0 \\
\hline
\end{tabular}

Figure 2

12-month growth rates: by division, June 2007, with approximate 95 per cent confidence intervals, July 2006 to June $2007^{1}$

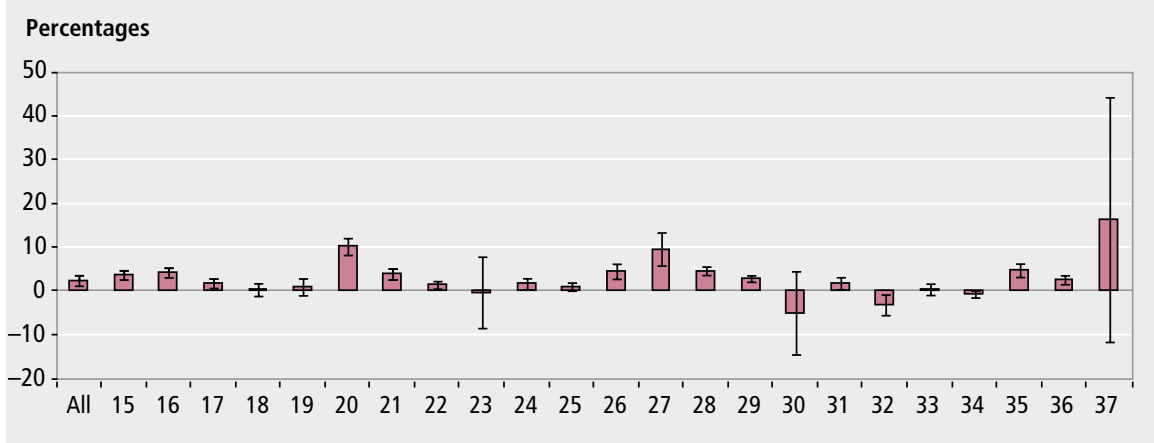

Note:

1 12-month average. per cent confidence interval of \pm 2 standard errors calculated from the individual observations of interest at a divisional level. As with the month-on-month growth rates, the same null hypothesis can be tested on the 12-month growth rates. The null hypothesis, that the growth rate equals zero, should be retained for only seven divisions, four of which with caution, as the narrow intervals are approximate and are very close to zero. For divisions 23,30 and 37, the data show no strong evidence to suggest a nonzero growth rate. The difference in results from the month-on-month and 12-month growth rates illustrates the distinguishable movement over the year, as mentioned above.

\section{Net sector output}

The same basic price information was used to feed into each of the PPI series using different weighting structures. The overall standard error for the month-on-month growth rate of the net sector output (NSO) PPI (including duty) was 0.1 percentage points. The 12-month growth rate had a standard error of 0.5 percentage points. These are lower than the respective GSO standard errors (0.2 and 0.6, respectively).

\section{PPI cut in sample size}

The first of three phases to cut the PPI sample size was completed in March 2007. As a result, the standard errors calculated between July 2006 and June 2007 have used a slightly smaller sample size to that of the previous year's analysis.

There was very little difference between the month-on-month standard errors calculated in June 2006 and June 2007. Two-thirds of the divisions, including the GSO, have unchanged standard errors, at one decimal place, from the previous year. Division 37 saw the largest change in standard error, where it has decreased from 3.9 to 3.1, improving the accuracy of this year's estimate for division 37 . The reduction in the sample size of the PPI has not had a visible effect on the month-onmonth standard errors.

The reduction of the sample size has had little effect on the quality of the index. The 12-month standard errors in June 2007 are very similar to those produced for June 2006. Division 23 saw the largest change in standard error, with a decrease of 0.4 percentage points from June 2006.

The reduction in the sample size has had no visible effect on the NSO PPI standard errors, as they have remained unchanged, at one decimal place, from those published for the year ending June 2006. 
Most of the sample cut was applied in phases two and three, so the full effect of reducing the sample size will not be seen until next year's analysis for July 2007 to June 2008. The reallocation of the sample should substantially, or completely, negate the effect on the standard error of the reduction in sample size. The confirmation of this, or otherwise, will be presented in next year's article.

Further information on this survey is shown in the PPI Summary Quality Report on the National Statistics website at www.statistics.gov.uk/about/data/ methodology/quality/information_ business_statistics.asp

\section{CONTACT}

网 elmr@ons.gsi.gov.uk

\section{REFERENCES}

Morris J and Green T (2007): 'Measuring the quality of the producer price index', Economic \& Labour Market Review 1(10), pp 31-5.

Wood J, Šova M G and Bucknall R D (2008):

'The method used to estimate standard errors for UK producer price indices', Survey Methodology Bulletin No.62, March 2008, pp 62-80. 